Check for updates

Cite this: RSC Adv., 2019, 9, 35636

Received 27th September 2019 Accepted 28th October 2019

DOI: 10.1039/c9ra07843f

rsc.li/rsc-advances

\section{Key role of hydrochar in heterogeneous photocatalytic degradation of sulfamethoxazole using $\mathrm{Ag}_{3} \mathrm{PO}_{4}$-based photocatalysts ${ }^{\dagger}$}

\begin{abstract}
Li Zhou, (D) ab Min Cai, ${ }^{\text {ab }}$ Xu Zhang, ${ }^{\text {ab }}$ Naxin Cui, ${ }^{\text {ab }}$ Guifa Chen ${ }^{\text {ab }}$ and Guo-yan Zou ${ }^{\text {ab }}$
To overcome the practical application limitations of $\mathrm{Ag}_{3} \mathrm{PO}_{4}$ such as photocorrosion and relatively low efficiency of photogenerated carrier seperation, $\mathrm{Ag}_{3} \mathrm{PO}_{4}$ particles were loaded onto hydrochar. The particles in the composite had a smaller crystallite size and different phase structure with more edges than pure $\mathrm{Ag}_{3} \mathrm{PO}_{4}$ particles. The as-prepared composite catalyst exhibited a different photocatalytic performance for sulfamethoxazole (SMX) degradation when varying the mass ratio of hydrochar and $\mathrm{Ag}_{3} \mathrm{PO}_{4}$. In addition to higher SMX degradation efficiency, the composite exhibited much higher TOC degradation efficiency, recycling stability, and less-toxic intermediate production. The composites enhanced visible light response, and accelerated electron transfer and photogenerated carrier separation as well. The addition of $\mathrm{H}_{2} \mathrm{O}_{2}$ to the photocatalytic system enhanced the photocatalytic activity of the composite catalyst. According to a mechanistic examination, the hole $\left(\mathrm{h}^{+}\right)$is the dominant reactive species for SMX degradation. This study provides new insight into high-efficiency, low cost, and easily prepared photocatalysts for pollution removal from water.
\end{abstract}

\section{Introduction}

To increase the utilization of solar light in the process of photocatalytic activities, the development of visible-light responsive photocatalysts has drawn much attention recently. Due to $\mathrm{Ag}_{3} \mathrm{PO}_{4}$ having a more than $90 \%$ quantum efficiency at wavelengths $>420 \mathrm{~nm}, \mathrm{Ag}_{3} \mathrm{PO}_{4}$-based photocatalysts have attracted great attention. ${ }^{1}$ Although $\mathrm{Ag}_{3} \mathrm{PO}_{4}$ exhibits high photocatalytic activities for organic matter degradation in polluted water under visible light irradiation, it has serious drawbacks, namely, low efficiency of photogenerated carrier seperation and photocorrosion, resulting in $\mathrm{Ag}^{\mathrm{O}}$ deposition and slow dissolution $\left(\sim 0.02 \mathrm{~g} \mathrm{~L}^{-1}\right) .{ }^{2}$ These are the main obstacles in using $\mathrm{Ag}_{3} \mathrm{PO}_{4}$ for practical applications.

Recently, much effort has been put forward further optimizing the photocatalytic activity and improving the stability of $\mathrm{Ag}_{3} \mathrm{PO}_{4}$. An effective method to increase photocatalytic activity and stability of photocatalysts is synthesizing composite materials. Different types of materials, such as g- $\mathrm{C}_{3} \mathrm{~N}_{4},{ }^{3} \mathrm{GO},{ }^{4} \mathrm{MnO}_{x},{ }^{5}$ $\mathrm{TiO}_{2-x},{ }^{6} \mathrm{WO}_{3},{ }^{7} 3 \mathrm{DOM}-\mathrm{SrTiO}_{3},{ }^{8}$ and $\mathrm{AgX}(\mathrm{X}=\mathrm{Cl}, \mathrm{Br}, \mathrm{I}),{ }^{9-11}$ have been applied to synthesize $\mathrm{Ag}_{3} \mathrm{PO}_{4}$-based composite

${ }^{a}$ Institute of Eco-environment and Plant Protection, Shanghai Academy of Agricultural Sciences, Shanghai 201403, China.E-mail: zouguoyan@263.net; joly.zhouli@gmail. com; Tel: +8618817365817

${ }^{b}$ Shanghai Engineering Research Centre of Low-carbon Agriculture, Shanghai 201403, China

† Electronic supplementary information (ESI) available. See DOI: 10.1039/c9ra07843f photocatalysts. The incorporated materials not only inhibit the photogenerated carrier's recombination and enhance photocatalytic activity, but also increase stability and decrease photocorrosion of $\mathrm{Ag}_{3} \mathrm{PO}_{4}$. However, the large scale applications of such composite materials need low preparation expenses, renewability, and excellent photocatalytic performance. ${ }^{\mathbf{1 2}}$ Therefore, it is required to further develop novel supporting or incorporating materials to enhance photocatalytic performance and stability of $\mathrm{Ag}_{3} \mathrm{PO}_{4}$.

Biochar is generated from waste biomass carbonization via pyrolysis and hydrolysis. The produced biochar is a type of lowcost and stable material and has been applied in many fields. ${ }^{13}$ Usually in a typical biochar, the carbon, hydrogen, and oxygen content are in the range of $45-60,2-5$, and $10-20 \mathrm{wt} \%$, respectively. ${ }^{\mathbf{1 4 , 1 5}}$ The biochar contains some hydrophilic/ hydrophobic functional groups and aromatic carbon structure, that can favor reaction with other functional material or adsorption of organic pollutants. The condensed aromatic ring and quinone moieties structure of biochar can promote electron shuttling and storage. ${ }^{12}$ Biochar has unique characteristics, such as electrical conductivity, abundant functional groups, and chemical stability, which are beneficial to photocatalysis process when combine biochar with photocatalysts. ${ }^{12}$ The incorporation of pyrochar, produced through the pyrolysis method, can improve the photocatalytic activity of many photocatalysts, including $\mathrm{TiO}_{2},{ }^{16} \mathrm{Fe}_{3} \mathrm{O}_{4} / \mathrm{BiOBr},{ }^{17}$ and $\mathrm{Ag} / \mathrm{Ag}_{3} \mathrm{PO}_{4} \cdot{ }^{18} \mathrm{It}$ has been reported that $80 \%$ of amoxicillin decomposition occurred in $120 \mathrm{~min}$ with a composite of $\mathrm{Ag} / \mathrm{Ag}_{3} \mathrm{PO}_{4} /$ pyrochar, compared to $65 \%$ of amoxicillin degradation with pure 
$\mathrm{Ag}_{3} \mathrm{PO}_{4} \cdot{ }^{18}$ The hydrolysis method, different from pyrolysis, may result in a different chemical structure and properties. ${ }^{\mathbf{1 9}}$ Hydrochar possesses a greater abundance of defects and oxygenerated functional groups, including hydroxyl, ether, and carboxyl groups than pyrochar does. ${ }^{20}$ Furthermore, some studies have reported that hydrochar could adsorb more organic pollutants including phenanthrene, 17a-ethinylestradiol, and bisphenol A than pyrochar could. ${ }^{21}$ Based on these advantages, the composite hydrochar $/ \mathrm{TiO}_{2}$ demonstrated superior visible-light photocatalytic activity in contrast to carbon/ $/ \mathrm{TiO}_{2}$ with high technology carbon, such as fullerene and carbon nanotubes. ${ }^{22}$ However, to date, few studies have used hydrochar as a photocatalyst support or incorporated materials to investigate the synergistic effects of photodegradation on organic pollutants.

Owing to the potential antibacterial resistance, one of a source of environmental pollutants, antibiotics, has raised much concerns. Sulfamethoxazole (SMX), a typical sulfonamide antibiotic, is widely used in human and animal disease treatment and aquaculture. With high water solubility and low adsorption capacity, SMX is difficult to remove by simple photodegradation or adsorption methods. ${ }^{23}$ Photocatalysis technology has proven its potential in the degradation of SMX from aqueous matrices. Moreover, as opposed to dyes, SMX can not absorb visible light at the wavelengths greater than $400 \mathrm{~nm},{ }^{24}$ which casts SMX as an appropriate target pollutant with which to examine the photocatalytic activity of visible-light responsive materials. ${ }^{16,25}$

In the present work, the hydrothermal carbonization method was employed to prepare hydrochar from woodchips, and a chemical precipitation method was used to synthesize $\mathrm{Ag}_{3} \mathrm{PO}_{4}$-based composites with different hydrochar ratios. SMX was used as the target pollutant to examine the adsorption capacity and photocatalytic degradation efficiency of $\mathrm{Ag}_{3} \mathrm{PO}_{4} /$ hydrochar composites under visible light. A potential photocatalytic degradation mechanism was proposed based on the radical scavenging experiments of a reactive species and electrochemical impedance spectroscopy (EIS), as well as on an electron spin resonance (ESR) analysis. The stability and reusability of photocatalysts, mineralization, and combined toxicity of intermediate products produced during the degradation process were evaluated for the practical application of the $\mathrm{Ag}_{3} \mathrm{PO}_{4} /$ hydrochar composite.

\section{Experimental}

\subsection{Chemicals}

Sulfamethoxazole was bought from Sigma-Aldrich (USA). All of the other reagents, such as disodium hydrogen phosphate $\left(\mathrm{Na}_{2} \mathrm{HPO}_{4}, \geq 99.0 \%\right)$, silver acetate $\left(\mathrm{CH}_{3} \mathrm{COOAg}, \geq 99.0 \%\right)$, hydrogen peroxide $\left(\mathrm{H}_{2} \mathrm{O}_{2}, 30 \%\right)$, 5,5-dimethyl-1-pyrrolidine $\mathrm{N}$ oxide (DMPO, $\geq 97.0 \%$ ), isopropanol ( $\geq 99.7 \%$ ), disodium ethylenediaminetetraacetic (EDTA-Na $2, \geq 99.0 \%$ ), $p$-benzoquinone $(\geq 98.0 \%$ ), and acetonitrile (HPLC grade, $\geq 99.8 \%$ ) were bought from Sinopharm Chemical Reagent Co. Ltd. (Shanghai, China). Each of the chemicals was utilized as received sans additional purification. In the process of experiments, double-distilled water was used all the time.

\subsection{Hydrochar preparation}

Wood sticks were collected from Osmanthus fragrans growing in the courtyard of the Shanghai Academy of Agricultural Sciences (E:121.48 ${ }^{\circ}, \mathrm{N}: 30.95^{\circ}$ ) in June 2018. The woodchips collected were thoroughly washed to remove dust and then air dried for $48 \mathrm{~h}$. Before the hydrothermal carbonization process, a pulverizer was used to carefully break the dried woodchips to pass through a 100-mesh sieve. To synthesize the hydrochar, $6 \mathrm{~g}$ of biomass powder was dispersed into $60 \mathrm{~mL}$ of double-distilled water by ultrasonic stirring for $1 \mathrm{~h}$. The mixture was then moved into a $100 \mathrm{~mL}$, Teflon ${ }^{\mathrm{TM}}$-lined stainless steel autoclave and the vessel was heated in an electric oven at $200{ }^{\circ} \mathrm{C}$ for $5 \mathrm{~h}$. The hydrothermal hydrochar was centrifuged and the precipitate was washed with double-distilled water and ethanol and then dried at $100{ }^{\circ} \mathrm{C}$. Following synthesis, the hydrochar sample was stored in the dark before being used.

\subsection{Photocatalysts preparation}

In a typical synthesis of a hydrochar $/ \mathrm{Ag}_{3} \mathrm{PO}_{4}$ composite, a specific amount of hydrochar was dispersed into a mixture of

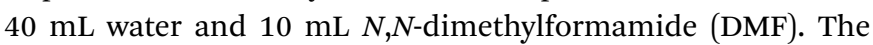
above mixture was then sonicated for $4 \mathrm{~h}$. A solution of $60 \mathrm{~mL}$ $\mathrm{CH}_{3}$ COOAg $(0.03 \mathrm{M})$ was added to the hydrochar suspension under vigorous magnetic stirring for $1 \mathrm{~h}$. Ultimately a precipitate generated after adding dropwise $4 \mathrm{~mL}$ of $0.15 \mathrm{M} \mathrm{Na}_{2} \mathrm{HPO}_{4}$ solution under vigorous stirring. The precipitate was separated and washed for 3 times with distilled water and anhydrous ethanol respectively and then dried under vacuum at $80^{\circ} \mathrm{C}$. The amounts of added hydrochar were $0.05,0.1,0.2$, and $0.3 \mathrm{~g}$, and the obtained compost samples were labeled as $0.05 \mathrm{C} / \mathrm{Ag}_{3} \mathrm{PO}_{4}$, $0.1 \mathrm{C} / \mathrm{Ag}_{3} \mathrm{PO}_{4}, 0.2 \mathrm{C} / \mathrm{Ag}_{3} \mathrm{PO}_{4}$, and $0.3 \mathrm{C} / \mathrm{Ag}_{3} \mathrm{PO}_{4}$, in which the mass ratio of hydrochar $/ \mathrm{Ag}_{3} \mathrm{PO}_{4}$ were $0.2,0.4,0.8$, and 1.2 , respectively. Pure $\mathrm{Ag}_{3} \mathrm{PO}_{4}$ particles were also prepped beneath identical conditions, but without adding hydrochar.

\subsection{Material characterization}

The surface morphologies of samples were characterized by scanning electron microscopy (SEM) using Nova NanoSem 450 devices at $15 \mathrm{kV}$ produced by FEI company. The crystal structure of as-synthesized samples was ascertained by Bruker D8 Advance diffractometer with $\mathrm{Cu}-\mathrm{K} \alpha$ radiation source $(\lambda=$ $0.15406 \mathrm{~nm})$ in the range $10-80^{\circ}(2 \theta)$ at rate of $4^{\circ} \mathrm{min}^{-1}$ at $40 \mathrm{kV}$ and $40 \mathrm{~mA}$. Fourier transform infrared spectra (FT-IR) of the samples were recorded by a Nicolet 5700 spectrometer (Thermo, USA) equipped with a $\mathrm{KBr}$ beam splitter at room temperature in the range of $4000-400 \mathrm{~cm}^{-1}$ with the resolution of $2 \mathrm{~cm}^{-1}$. The elements' binding energies of samples were conducted on basis of the X-ray photoelectron spectroscopy (XPS) using an upgraded RBD PHI-5000C ESCA system (PerkinElmer) with Mg-Ka radiation $(h=1253.6 \mathrm{eV})$. The ultraviolet-visible reflectance spectra (UV-vis DRS) in the range of 200-800 $\mathrm{nm}$ were recorded by a LAMBDA 950 spectrometer (PerkinElmer) with an integrating sphere and $\mathrm{BaSO}_{4}$ used as a reference. A Bruker E500 
spectrometer was used to record electron spin resonance (ESR) signals of spin-trapped paramagnetic materials with a resonance frequency of $9.77 \mathrm{GHz}$, modulation frequency of $100 \mathrm{kHz}$, microwave power of $20.02 \mathrm{~mW}$, modulation amplitude of $1.0 \mathrm{G}$, and sweep width of $100 \mathrm{G}$. A CHI760E (Chenhua Instrument Co., Shanghai, China) electrochemical workstation was used to record electrochemical impedance spectroscopy (EIS) spectra in a three-electrode system. $\mathrm{Ag} / \mathrm{AgCl}$ and $\mathrm{Pt}$ were used as the reference electrode and counterelectrode, respectively. The analysis was conducted at an open circuit potential with $5 \mathrm{mV}$ AC amplitude in the frequency range of $0.1 \mathrm{~Hz}$ to $100 \mathrm{kHz}$. Nitrogen adsorption isotherms were measured on a automatic specific surface area and pore analyzer (Micromeritics Instrument Corporation, ASAP2460) at $77.3 \mathrm{~K}$ after degassing for $2 \mathrm{~h}$ at $373.15 \mathrm{~K}$. The hydrochar $/ \mathrm{Ag}_{3} \mathrm{PO}_{4}$ composite samples were characterizedby high spectral resolution confocal Raman Microscope (HORIBA LabRam HR Evolution) equipped with a $514 \mathrm{~nm}$ laser excitation source.

\subsection{Evaluation of photocatalytic activity}

The photocatalytic performance of composites was evaluated by SMX degradation under visible light irradiation in a doublelayer reactor (500 $\mathrm{mL}$ volume and $8 \mathrm{~cm}$ diameter) with cooling water circulation to keep reaction temperature at $25 \pm 2{ }^{\circ} \mathrm{C}$. In a typical process, $20 \mathrm{mg}$ of photocatalyst was suspended in the SMX solution ( $1 \mathrm{mg} \mathrm{L}^{-1}, 200 \mathrm{~mL}$ ) and the solution was stirred for $60 \mathrm{~min}$ in the dark for achieving adsorption-desorption equilibrium. A 300-W xeon lamp with a cutoff filter $(\lambda>420 \mathrm{~nm})$ served as the visible-light irradiation source and was positioned $30 \mathrm{~cm}$ from the liquid level. The lamp had a mean horizontal light intensity of $180 \mathrm{~mW} \mathrm{~cm} \mathrm{~cm}^{-2}$ to trigger photocatalytic reactions. A certain volume of sample was withdrawn at selected time during the process and then filtered using $0.22 \mu \mathrm{m}$ syringe filters for SMX analysis by a high-performance liquid chromatograph (HPLC) at $\lambda_{\max } 265 \mathrm{~nm}$ (Waters, USA), with acetonewater $(30: 70, \mathrm{v} / \mathrm{v})$ serving as the mobile phase at a flow rate of

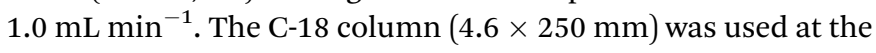
temperature of $30{ }^{\circ} \mathrm{C}$ with injection volume of $10 \mu \mathrm{L}$. To ascertain the effect of reactive species for photocatalytic process, three scavengers, $10 \mathrm{mM}$ isopropanol, $0.5 \mu \mathrm{M}$ benzoquinone, and $5 \mathrm{mM}$ disodium ethylenediaminetetraacetate (EDTA-Na ${ }_{2}$ ), were added separately to the SMX solutions $\left(1 \mathrm{mg} \mathrm{L}^{-1}\right)$ which contained $0.1 \mathrm{~g} \mathrm{~L}^{-1}$ of photocatalyst. The other experiment followed the identical procedure as the photodegradation experimental process.

\subsection{Photocatalyst stability}

The stability and reusability of $\mathrm{Ag}_{3} \mathrm{PO}_{4}$ and $0.1 \mathrm{C} / \mathrm{Ag}_{3} \mathrm{PO}_{4}$ composites were conducted by SMX cyclic degradation experiments. Compared to the typical photocatalytic experiment, the cyclic tests elevated the concentrations of photocatalysts and SMX to $C_{\text {catalyst }}=0.25 \mathrm{~g} \mathrm{~L}^{-1}$ and $C_{\mathrm{SMX}}=5 \mathrm{mg} \mathrm{L}^{-1}$ to offset the impact of the loss of photocatalysts during recycling process. After each cycle, the photocatalyst was collected by filtration and then was used for the following cyclic experiment after washing and drying.

\section{Results and discussion}

\subsection{Characterization of hydrochar/ $/ \mathrm{Ag}_{3} \mathrm{PO}_{4}$}

Fig. 1(a-c) show typical SEM images of hydrochar, $\mathrm{Ag}_{3} \mathrm{PO}_{4}$, and $0.1 \mathrm{C} / \mathrm{Ag}_{3} \mathrm{PO}_{4}$, respectively. The as-prepared hydrochar has a rough, porous, and fibrous surface and pure $\mathrm{Ag}_{3} \mathrm{PO}_{4}$ particles are irregular spheres with an average diameter of about $593 \mathrm{~nm}$ (Fig. S1(a)†). Interestingly, using the same synthesized method, the $\mathrm{Ag}_{3} \mathrm{PO}_{4}$ particles in the composite hydrochar $/ \mathrm{Ag}_{3} \mathrm{PO}_{4}$ have a cubic morphology with an smaller average particle size of around 298, 303, 256 and $238 \mathrm{~nm}$ for $0.05 \mathrm{C} / \mathrm{Ag}_{3} \mathrm{PO}_{4}, 0.1 \mathrm{C} /$ $\mathrm{Ag}_{3} \mathrm{PO}_{4}, 0.2 \mathrm{C} / \mathrm{Ag}_{3} \mathrm{PO}_{4}$, and $0.3 \mathrm{C} / \mathrm{Ag}_{3} \mathrm{PO}_{4}$, respectively. (Fig. S1(be) $\dagger$ ), indicating that with more hydrochar introduction, the particle size decreased gradually. As shown in Fig. 1 and $\mathrm{S} 2, \uparrow$ the $\mathrm{Ag}_{3} \mathrm{PO}_{4}$ particles in the pure $\mathrm{Ag}_{3} \mathrm{PO}_{4}$ aggregated, whereas those in the composite with different shapes and sizes were well dispersed in hydrochar $/ \mathrm{Ag}_{3} \mathrm{PO}_{4}$ composite with less hydrochar incorporation (0.05-0.2C/Ag $\left.{ }_{3} \mathrm{PO}_{4}\right)$. While in the $0.3 \mathrm{C} / \mathrm{Ag}_{3} \mathrm{PO}_{4}$, the particles aggregated again due to the large amounts of biochar incorporation. The introduction of hydrochar had significant effects on the phase structure and crystallite size of $\mathrm{Ag}_{3} \mathrm{PO}_{4}$, which differs from previous reports ${ }^{18}$ - probably due to the different method of synthesis and type of biochar. Yan et al. reported that cubic $\mathrm{Ag}_{3} \mathrm{PO}_{4}$ was synthesized in the presence of ammonia, and quasi-spherical $\mathrm{Ag}_{3} \mathrm{PO}_{4}$ particles were formed in the absence of ammonia. ${ }^{26}$ In the system with ammonia, an $\left[\mathrm{Ag}\left(\mathrm{NH}_{3}\right)_{2}\right]^{+}$complex formed, which reduced the release rate of $\mathrm{Ag}^{+}$and subsequently reacted with $\mathrm{PO}_{4}{ }^{3-}$ anions to form $\mathrm{Ag}_{3} \mathrm{PO}_{4}$. In our experiments without hydrochar, the free $\mathrm{Ag}^{+}$ions present in the reaction system were in considerably high concentrations such that the growth process of $\mathrm{Ag}_{3} \mathrm{PO}_{4}$ crystals was spontaneous and fast and lead to the rapid nucleation and irregularly spherical morphology of $\mathrm{Ag}_{3} \mathrm{PO}_{4}$ crystals. In contrast, in the presence of hydrochar, the free $\mathrm{Ag}^{+}$could be absorbed by hydrochar and the free $\mathrm{Ag}^{+}$would gradually be released into reaction system, which would slow the nucleation and different growth rates of $\mathrm{Ag}_{3} \mathrm{PO}_{4}$ crystals, resulting in the production of more crystalline structures. ${ }^{27}$

Although the $\mathrm{Ag}_{3} \mathrm{PO}_{4}$ particles have different shapes and sizes in the pure and composite samples, the XRD patterns [Fig. 2(a)] obviously reveal that each of the diffraction peaks of the samples with irregular spherical and cube morphology can be indexed to the cubic $\mathrm{Ag}_{3} \mathrm{PO}_{4}$ (JCPDS card no. 06-0505), although the peaks of $0.3 \mathrm{C} / \mathrm{Ag}_{3} \mathrm{PO}_{4}$ were slightly shifted. The upshift of diffraction peaks of the $0.3 \mathrm{C} / \mathrm{Ag}_{3} \mathrm{PO}_{4}$ showed a lattice contraction due to the interaction between hydrochar and $\mathrm{Ag}_{3} \mathrm{PO}_{4} \cdot{ }^{28}$ No characteristic peaks of hydrochar were observed in the hydrochar $/ \mathrm{Ag}_{3} \mathrm{PO}_{4}$ composite pattern, which could be attributed to its relatively weak crystallinity and the low hydrochar quantity. No $\mathrm{Ag}^{0}$ peaks are evident in the XRD patterns of any of the photocatalysts, indicating that the hydrochar did not reduce $\mathrm{Ag}^{+}$to $\mathrm{Ag}^{0}$ during the preparation process.

The FT-IR spectra of pure hydrochar, pure $\mathrm{Ag}_{3} \mathrm{PO}_{4}$, and hydrochar $/ \mathrm{Ag}_{3} \mathrm{PO}_{4}$ composites are shown in Fig. 2(b). The abundant functional groups of hydrochar were identified from FT-IR spectra. The characteristic peaks at $1030-1160 \mathrm{~cm}^{-1}$ 


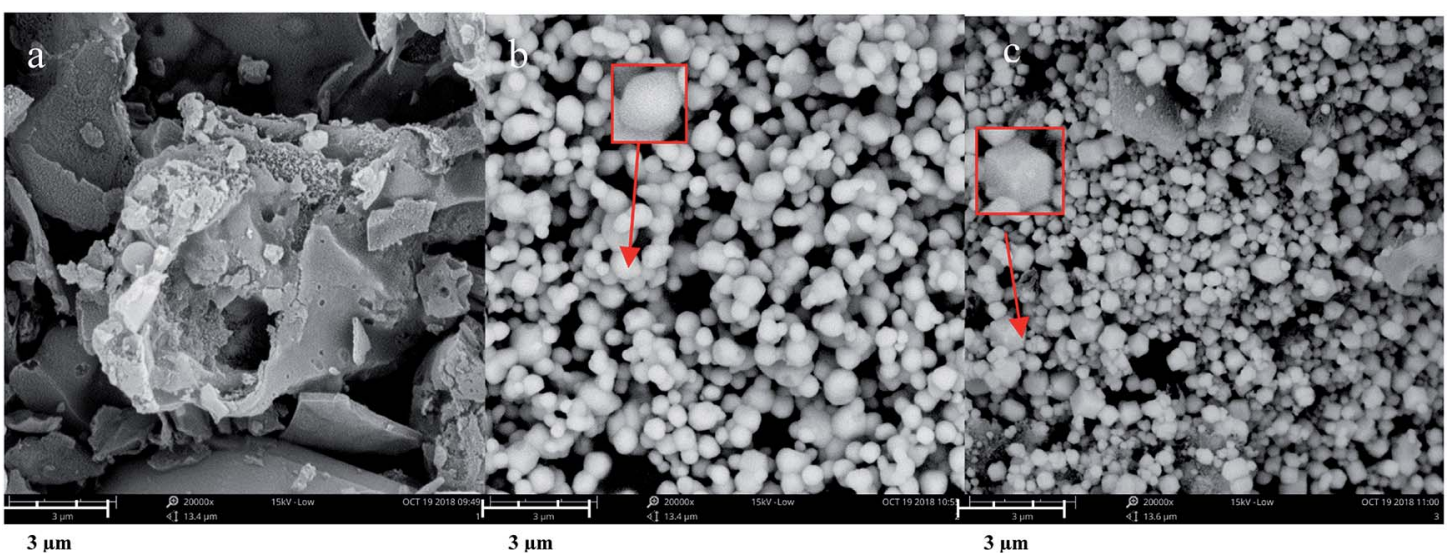

Fig. 1 SEM images of (a) hydrochar, (b) $\mathrm{Ag}_{3} \mathrm{PO}_{4}$, and (c) $0.1 \mathrm{C} / \mathrm{Ag}_{3} \mathrm{PO}_{4}$. The scale bar represents $3 \mu \mathrm{m}$.

represent the aliphatic $\mathrm{C}-\mathrm{O}$ and $\mathrm{C}-\mathrm{O}-\mathrm{C}$ stretching. ${ }^{29}$ The peaks at 1325 and $1600 \mathrm{~cm}^{-1}$ were ascribed to $\mathrm{O}-\mathrm{H}$ bending and aroic $\mathrm{C}=\mathrm{C}$ and $\mathrm{C}=\mathrm{O}$ stretching of conjugated ketones and quinones, ${ }^{30}$ respectively. The clear characteristic peaks at $\sim 1700$ and $2923-2851 \mathrm{~cm}^{-1}$, which were ascribed to $\mathrm{C}=\mathrm{O}$ stretching of carboxyl groups and $\mathrm{CH}_{3}$ carbon, ${ }^{20}$ respectively, were also observed for this hydrochar samples. The peak at $3420 \mathrm{~cm}^{-1}$ in hydrochar was due to $\mathrm{O}-\mathrm{H}$ stretching of hydroxyl groups because of absorbed water molecules. ${ }^{31}$ The above analysis revealed that much oxy-generated functional groups (hydroxyl groups and carboxyl groups etc.) existed in this hydrochar, which was beneficial to photocatalysts attachment. The infrared spectra of hydrochar $/ \mathrm{Ag}_{3} \mathrm{PO}_{4}$ (with cubic particles) are identical to that of pure $\mathrm{Ag}_{3} \mathrm{PO}_{4}$ (with irregular spherical particles), although the absorption peaks intensities decreased with the addition of hydrochar. The two peaks located at $1014 \mathrm{~cm}^{-1}$ and $559 \mathrm{~cm}^{-1}$ in the $\mathrm{Ag}_{3} \mathrm{PO}_{4}$ represent $\mathrm{P}-\mathrm{O}$ bond vibration. ${ }^{32}$ While with the addition of hydrochar, the peaks became weak and broad and meanwhile, the two peaks moved to 1028 and $555 \mathrm{~cm}^{-1}$ in $0.3 \mathrm{C} / \mathrm{Ag}_{3} \mathrm{PO}_{4}$, suggesting that the chemical bonds connections have changed and hydrochar and $\mathrm{Ag}_{3} \mathrm{PO}_{4}$ were connected together successfully. ${ }^{33}$

The surface compositions and chemical states of $\mathrm{Ag}_{3} \mathrm{PO}_{4}$ and $0.1 \mathrm{C} / \mathrm{Ag}_{3} \mathrm{PO}_{4}$ were established by XPS spectra. As can be seen in Fig. 2(c), mainly silver, oxygen, phosphorus, and carbon are present in both samples. A slightly stronger intensity of $\mathrm{C} 1 \mathrm{~s}$ in the sample of $0.1 \mathrm{C} / \mathrm{Ag}_{3} \mathrm{PO}_{4}$ than that of pure $\mathrm{Ag}_{3} \mathrm{PO}_{4}$ indicates the incorporation of hydrochar. The XPS spectra of pure $\mathrm{Ag}_{3} \mathrm{PO}_{4}$ and $0.1 \mathrm{C} / \mathrm{Ag}_{3} \mathrm{PO}_{4}$ were almost identical (as revealed in Fig. 2(d)), suggesting no formation of $\mathrm{Ag}^{0}$ or other chemical bonds. C 1s spectra (Fig. 2(e)) in $0.1 \mathrm{C} / \mathrm{Ag}_{3} \mathrm{PO}_{4}$ could be deconvoluted into two peaks. The peak at around $284.5 \mathrm{eV}$ is attributed to $\mathrm{sp}^{2}$ hybridized carbon and the other peak at around $286.2 \mathrm{eV}$ is assigned to some oxygen bound species such as $\mathrm{C}-\mathrm{OH}$ or (and) $\mathrm{C}-\mathrm{O}-\mathrm{C}{ }^{34}$ The $\mathrm{O} 1 \mathrm{~s}$ spectra (Fig. $2(\mathrm{f})$ ) in $0.1 \mathrm{C} / \mathrm{Ag}_{3} \mathrm{PO}_{4}$ could be deconvoluted into three peaks at around 530.6, 531.8 and $533.2 \mathrm{eV}$, which correspond to oxygen anions in the $\mathrm{P}-\mathrm{O}$ of $\mathrm{Ag}_{3} \mathrm{PO}_{4}$, hydroxyl oxygen and carboxyl oxygen, respectively. ${ }^{20,35}$ The XPS results showed that there are much hydroxyl and carboxyl groups existing in hydrochar and $\mathrm{Ag}_{3} \mathrm{PO}_{4}$ composit, consistent with the FT-IR data. Fig. $2(\mathrm{~g})$ shows Raman spectra of $\mathrm{Ag}_{3} \mathrm{PO}_{4}$, hydrochar and $0.1 \mathrm{C} / \mathrm{Ag}_{3} \mathrm{PO}_{4}$. In the spectrum of $\mathrm{Ag}_{3} \mathrm{PO}_{4}$, the obvious peak at 409 and $553 \mathrm{~cm}^{-1}$ was consistent with the symmetric stretching vibration of $\mathrm{P}-\mathrm{O}-\mathrm{P}$ bonds, and the peaks at $909 \mathrm{~cm}^{-1}$ were ascribed to the vibration of terminal oxygen of $\mathrm{PO}_{4} \cdot{ }^{3-5,36}$ In the spectrum of hydrochar, the peaks at 1378 and $1599 \mathrm{~cm}^{-1}$ were corresponded to the carbon-based material Dband (defects and disorder) and G-band (graphitic), respectively. In the spectrum of hydrochar $/ \mathrm{Ag}_{3} \mathrm{PO}_{4}$ composite, the presence of $\mathrm{D}$ and $\mathrm{G}$ bands and the characteristic peak at $909 \mathrm{~cm}^{-1}$ demonstrated the successful coupling of hydrochar to $\mathrm{Ag}_{3} \mathrm{PO}_{4}{ }^{37}$ The $\mathrm{D}$ and $\mathrm{G}$ peaks in the composite downshift to 1361 and $1579 \mathrm{~cm}^{-1}$, and the shift to lower energy of both the D and $\mathrm{G}$ modes in the composite is associated with the charge transfer from $\mathrm{Ag}_{3} \mathrm{PO}_{4}$ to hydrochar. ${ }^{38,39}$

\subsection{Photocatalytic properties and composite stability}

Using SMX as a target pollutant, photocatalytic performances of composites were evaluated to contrast the photocatalytic activities of $\mathrm{Ag}_{3} \mathrm{PO}_{4}$ with and without incorporating hydrochar under visible light irradiation. As presented on Fig. 3(a), in the process of $1 \mathrm{~h}$ adsorption before turning on the light, the removal rate of SMX by different samples are 9.97, 11.57, 14.86, 22.35 and $22.79 \%$ for $\mathrm{Ag}_{3} \mathrm{PO}_{4}, 0.05 \mathrm{C} / \mathrm{Ag}_{3} \mathrm{PO}_{4}, 0.1 \mathrm{C} / \mathrm{Ag}_{3} \mathrm{PO}_{4}, 0.2 \mathrm{C} / \mathrm{Ag}_{3} \mathrm{PO}_{4}$ and $0.3 \mathrm{C} / \mathrm{Ag}_{3} \mathrm{PO}_{4}$, respectively, indicating that the adsorption abilities of composites increase with the increased amounts of introduced hydrochar. However, the specific surface areas of composites are inconsistent with the adsorption capacities. The specific surface areas of photocatalysts are 3.84, 11.38, 9.83, 6.82 and $6.04 \mathrm{~m}^{2} \mathrm{~g}^{-1}$ for $\mathrm{Ag}_{3} \mathrm{PO}_{4}, 0.05 \mathrm{C} / \mathrm{Ag}_{3} \mathrm{PO}_{4}, 0.1 \mathrm{C} / \mathrm{Ag}_{3} \mathrm{PO}_{4}, 0.2 \mathrm{C} /$ $\mathrm{Ag}_{3} \mathrm{PO}_{4}$ and $0.3 \mathrm{C} / \mathrm{Ag}_{3} \mathrm{PO}_{4}$, respectively. The introduced hydrochar increase the specific surface area of composites compared with pure $\mathrm{Ag}_{3} \mathrm{PO}_{4}$, and with the increased amounts of hydrochar, the specific surface area decrease gradually maybe due to the aggregation of hydrochar. ${ }^{22,40}$ The results about specific surface area and adsorption capacity show that the adsorption of hydrochar does not depend on the physical adsorption, and the different functional groups (as shown in FT-IR and XPS results) contained by hydrochar can favor adsorption of organic 

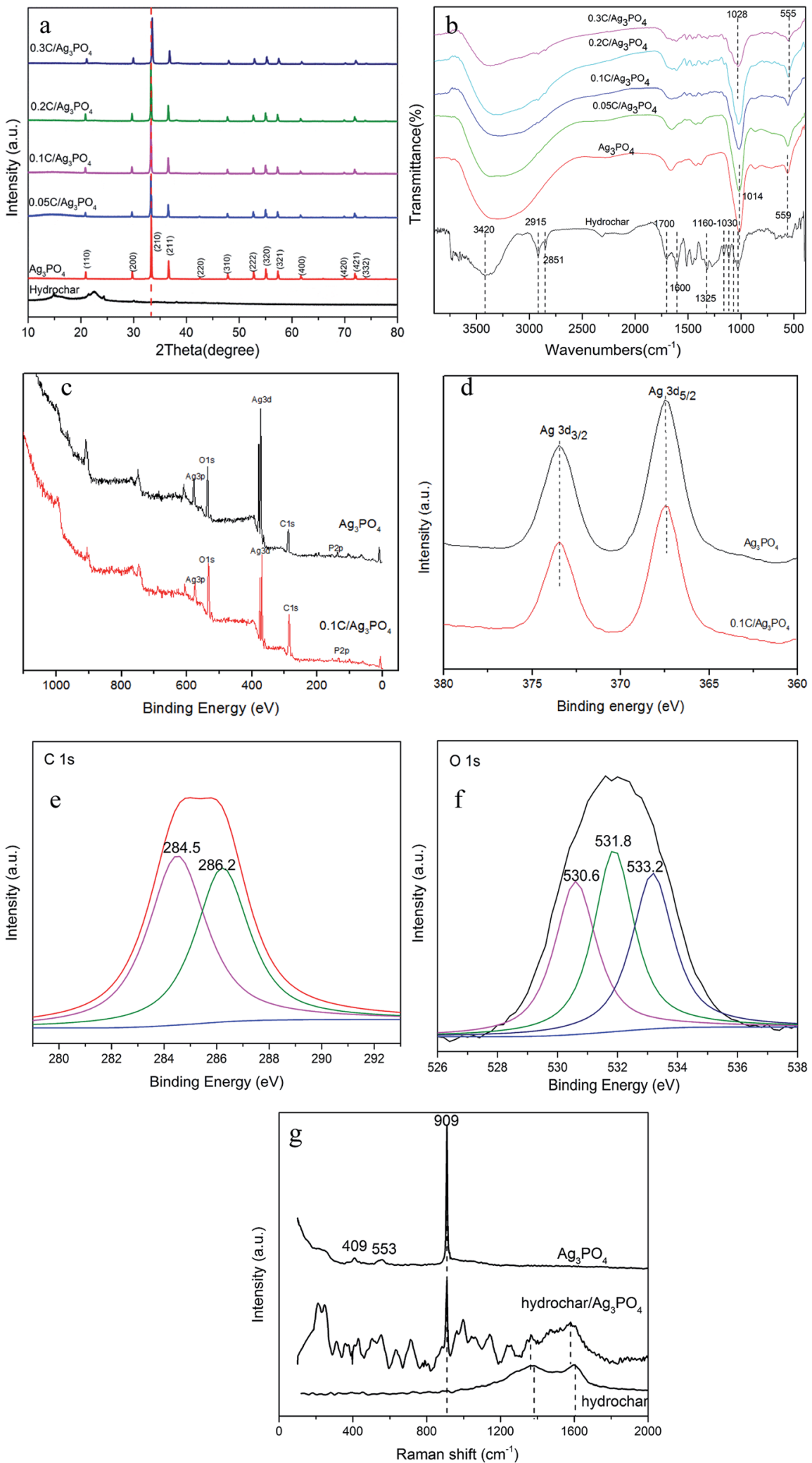

Fig. 2 (a) The XRD patterns; (b) FT-IR spectra of hydrochar, $\mathrm{Ag}_{3} \mathrm{PO}_{4}, 0.05-0.3 \mathrm{C} / \mathrm{Ag}_{3} \mathrm{PO}_{4}$; (c) XPS survey spectra of $\mathrm{Ag}_{3} \mathrm{PO}_{4}$ and $0.1 \mathrm{C} / \mathrm{Ag}_{3} \mathrm{PO} \mathrm{O}_{4}$; (d) high resolution XPS spectrum of $\mathrm{Ag} 3 \mathrm{~d}$ in $\mathrm{Ag}_{3} \mathrm{PO}_{4}$ and $0.1 \mathrm{C} / \mathrm{Ag}_{3} \mathrm{PO}_{4}$; (e and f) high resolution XPS spectrum of $\mathrm{C} 1 \mathrm{~s}$ and $\mathrm{O} 1 \mathrm{~s}$ in $0.1 \mathrm{C} / \mathrm{Ag}_{3} \mathrm{PO} \mathrm{O}_{4}$; (g) Raman spectra of $\mathrm{Ag}_{3} \mathrm{PO}_{4}$, hydrochar and $0.1 \mathrm{C} / \mathrm{Ag}_{3} \mathrm{PO}_{4}$.

pollutants through hydrogen bonding and/or electrostatic interactions. ${ }^{12}$ After turning on the light, the SMX concentration decreases slightly without a catalyst or with only hydrochar under visible light, suggesting that the photolysis and hydrochar photocatalytic degradation is negligible. When pure $\mathrm{Ag}_{3} \mathrm{PO}_{4}$ is used for the SMX degradation, around $48 \%$ of the 

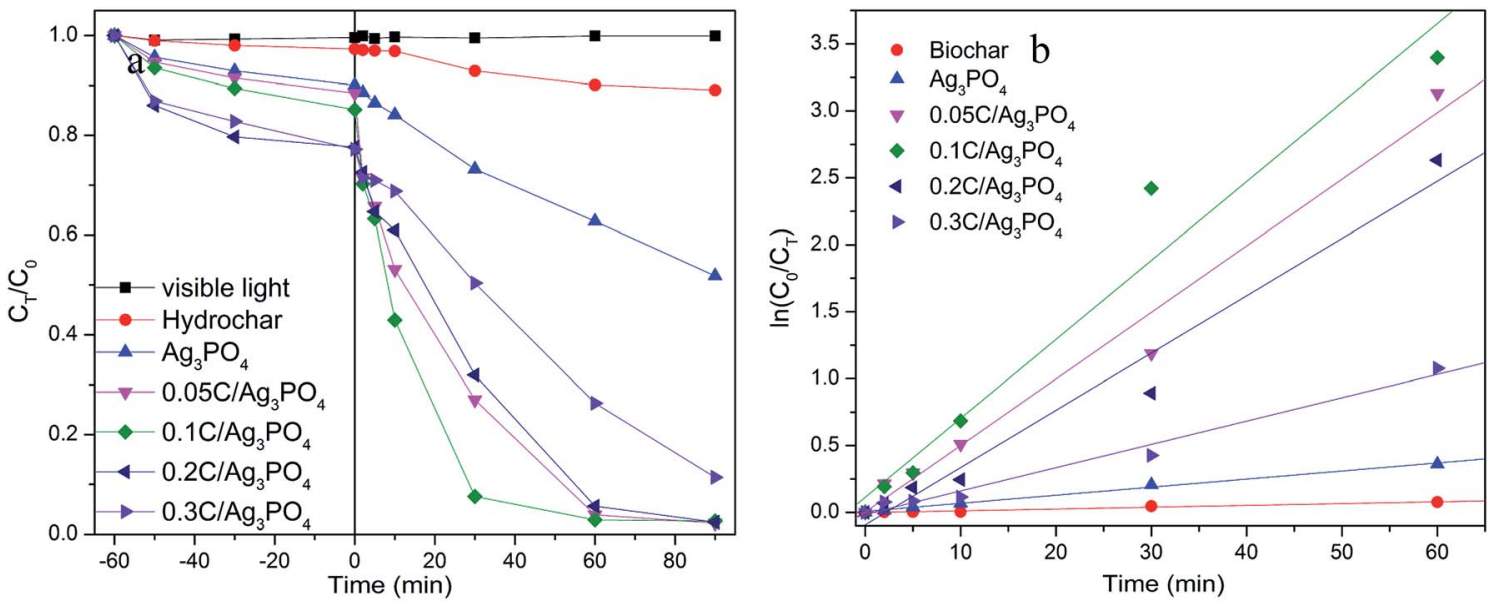

Fig. 3 (a) Removal of SMX in presence of various photocatalysts with different hydrochar and $\mathrm{Ag}_{3} \mathrm{PO}_{4}$ composition ratios under visible light irradiation, (b) photocatalytic rate of hydrochar/Ag $3 \mathrm{PO}_{4}$ for $\mathrm{SMX}$ degradation under visible light irradiation.

contaminant degrades in 90 min. In comparison, $98 \%$ SMX was degraded in the presence of the hydrochar $/ \mathrm{Ag}_{3} \mathrm{PO}_{4}$ composite under identical conditions. As revealed in Fig. $3(\mathrm{~b})$, the plots were linear fitted by $\ln \left(C_{0} / C_{\mathrm{T}}\right)$ versus irradiation time and the degradation rate constant is $0.001,0.006,0.050,0.059,0.043$, and $0.017 \mathrm{~min}^{-1}$ for hydrochar, pure $\mathrm{Ag}_{3} \mathrm{PO}_{4}, 0.05 \mathrm{C} / \mathrm{Ag}_{3} \mathrm{PO}_{4}$, $0.1 \mathrm{C} / \mathrm{Ag}_{3} \mathrm{PO}_{4}, 0.2 \mathrm{C} / \mathrm{Ag}_{3} \mathrm{PO}_{4}$, and $0.3 \mathrm{C} / \mathrm{Ag}_{3} \mathrm{PO}_{4}$, respectively. The $0.1 \mathrm{C} / \mathrm{Ag}_{3} \mathrm{PO}_{4}$ shows the highest degradation constant, which is attributed to the proper contact of $\mathrm{Ag}_{3} \mathrm{PO}_{4}$ and hydrochar. The amount of hydrochar has a significant impact on the photocatalytic activities of the hydrochar $/ \mathrm{Ag}_{3} \mathrm{PO}_{4}$ composite. When the hydrochar content is relatively low (0-2.3 wt\%), the photocatalytic activities of composite increases with the increment of hydrochar. However, when the hydrochar content is relatively high (2.3-6.7 wt\%), the photocatalytic activities of the composites decrease with further increase of the hydrochar content. Therefore, a proper amount of hydrochar may be important for electron transfer and the separation of holeelectron pairs of the composite photocatalysts. ${ }^{41}$

Furthermore, it is possible that the shape and surface structure of the $\mathrm{Ag}_{3} \mathrm{PO}_{4}$ particles improved the photocatalytic activities of the hydrochar $/ \mathrm{Ag}_{3} \mathrm{PO}_{4}$. Based on the aforementioned SEM outcomes, the $\mathrm{Ag}_{3} \mathrm{PO}_{4}$ particles of pure $\mathrm{Ag}_{3} \mathrm{PO}_{4}$ and hydrochar $/ \mathrm{Ag}_{3} \mathrm{PO}_{4}$ show different shapes and surface constructions. From the previous report, the photodegradation efficiency of the cubic $\mathrm{Ag}_{3} \mathrm{PO}_{4}$ was two times that of the spherical particles for $\mathrm{MO}$ and $\mathrm{RhB}$ degradation. The number of active sites will be remarkably increased because of the higher density of corners and edges on the surface of cubic particles and these sites facilitated the adsorption of organic molecules. ${ }^{27}$ Thus, the shape and surface structure of $\mathrm{Ag}_{3} \mathrm{PO}_{4}$ submicrocrystals could improve photocatalytic properties, which may be another reason that hydrochar $/ \mathrm{Ag}_{3} \mathrm{PO}_{4}$ could enhance the photocatalytic activities in contrast with $\mathrm{Ag}_{3} \mathrm{PO}_{4}$ without hydrochar. The results about the change of combined toxicity of produced intermediates and TOC removal rate (Fig. S3†) also indicate the role of incorporated hydrochar in the composite photocatalysts.
The reusability and stability of photocatalysts are vital to the practical application of photocatalytic techniques. As shown in Fig. 4(a), after three consecutive cycles, the photocatalytic degradation efficiency of $\mathrm{Ag}_{3} \mathrm{PO}_{4}$ without hydrochar decreased sharply from $68.2 \%$ to $31.1 \%$ after $90 \mathrm{~min}$ irradiation. However, only minor deactivation of the $0.1 \mathrm{C} / \mathrm{Ag}_{3} \mathrm{PO}_{4}$ was observed and the SMX removal rate decreased from $93.2 \%$ to $83.2 \%$, which implied the higher stability of the composite photocatalyst. The fresh and spent catalysts were also examined with XPS (Fig. 4(b)). The two peaks in the spectra of $\mathrm{Ag}_{3} \mathrm{PO}_{4}$ and $0.1 \mathrm{C} /$ $\mathrm{Ag}_{3} \mathrm{PO}_{4}$, corresponding to the $\mathrm{Ag} 3 \mathrm{~d}_{3 / 2}$ and $\mathrm{Ag} 3 \mathrm{~d}_{5 / 2}$ binding energies of $\mathrm{Ag}^{+}$, located at 368 and $374 \mathrm{eV}^{42} \mathrm{The} \mathrm{Ag} 3 \mathrm{~d}_{3 / 2}$ and $\mathrm{Ag}$ $3 \mathrm{~d}_{5 / 2}$ peaks of $\mathrm{Ag}_{3} \mathrm{PO}_{4}$ without hydrochar showed clear reduction and upshift after three cycles of photocatalytic reactions. The $1.1 \mathrm{eV}$ upshift implied obvious metallic $\mathrm{Ag}$ production in the process of photocatalytic reaction of $\mathrm{Ag}_{3} \mathrm{PO}_{4}$. For the $0.1 \mathrm{C} /$ $\mathrm{Ag}_{3} \mathrm{PO}_{4}$, the $\mathrm{Ag} 3 \mathrm{~d}_{3 / 2}$ and $\mathrm{Ag} 3 \mathrm{~d}_{5 / 2}$ peaks show a small decrease and an $0.3 \mathrm{eV}$ upshift. This indicates that less $\mathrm{Ag}^{+}$in $0.1 \mathrm{C} /$ $\mathrm{Ag}_{3} \mathrm{PO}_{4}$ was reduced into metallic $\mathrm{Ag}$ compared to $\mathrm{Ag}_{3} \mathrm{PO}_{4}$ without hydrochar. According to the previous report, ${ }^{43}$ a significant loss of $\mathrm{Ag}^{+}$ions from the $\mathrm{Ag}_{3} \mathrm{PO}_{4}$ sharply decreases its photocatalytic activity. The changes of Ag $3 \mathrm{~d}$ XPS peaks could explain the progressive decline of the photocatlaytic degradation performances. Therefore, incorporating hydrochar with the $\mathrm{Ag}_{3} \mathrm{PO}_{4}$ photocatalyst not only enhances the photocatalytic performance of composites, but also promotes the stability and durability of the photocatalytic activity by preventing the photocorrosion.

\subsection{Mechanism analysis}

The light absorbance of the hydrochar, pure $\mathrm{Ag}_{3} \mathrm{PO}_{4}$, and hydrochar $/ \mathrm{Ag}_{3} \mathrm{PO}_{4}$ composite is shown in Fig. 5(a). The absorption edge of the pure $\mathrm{Ag}_{3} \mathrm{PO}_{4}$ is $\sim 538 \mathrm{~nm}$, while all of the hydrochar $/ \mathrm{Ag}_{3} \mathrm{PO}_{4}$ composites show a wider absorption in the visible light region. The absorption edge of $0.1 \mathrm{C} / \mathrm{Ag}_{3} \mathrm{PO}_{4}$ is at $\sim 823 \mathrm{~nm}$, which is broader than that of the pure $\mathrm{Ag}_{3} \mathrm{PO}_{4}$. Accordingly, $0.1 \mathrm{C} / \mathrm{Ag}_{3} \mathrm{PO}_{4}$ and $\mathrm{Ag}_{3} \mathrm{PO}_{4}$ has a band gap $\left(E_{\mathrm{g}}\right)$ of 1.5 

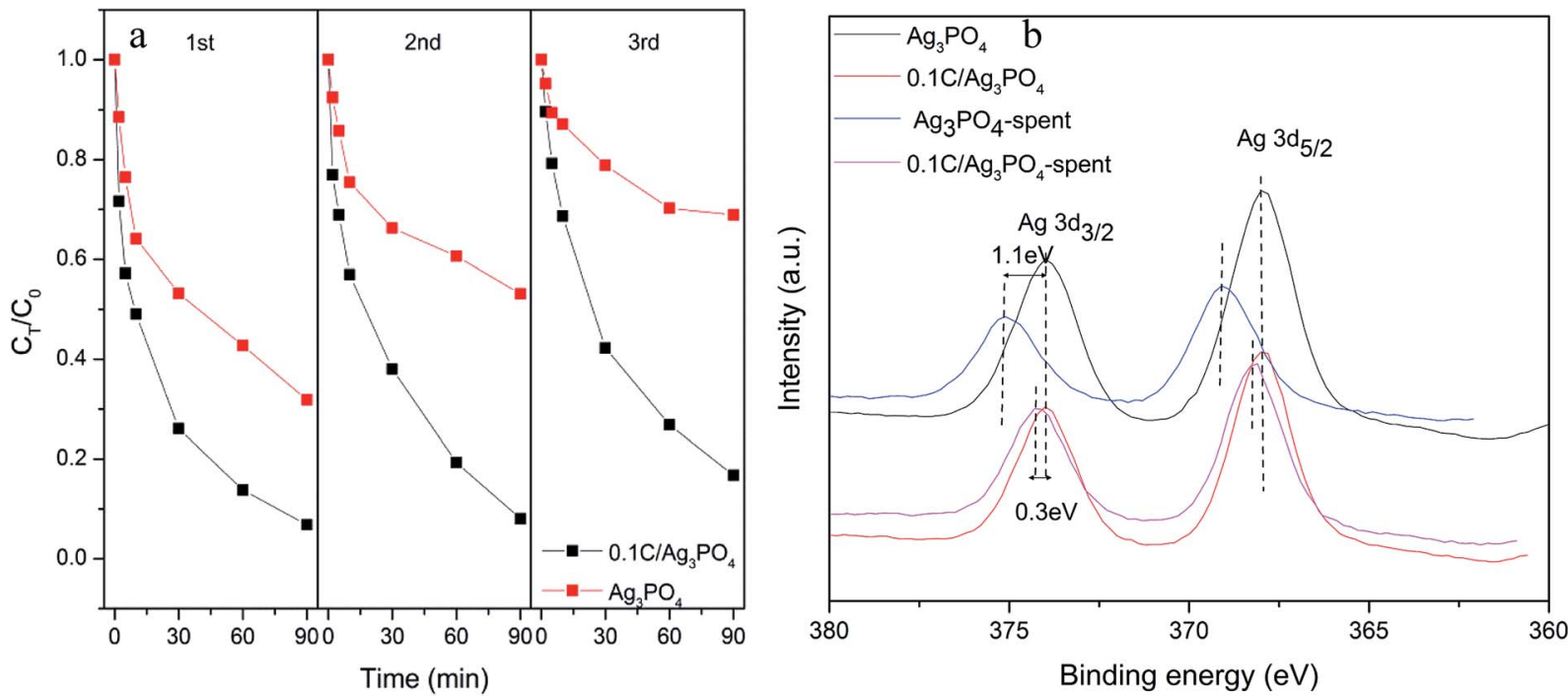

Fig. 4 (a) The cycling performance of photocatalytic degradation of $\mathrm{SMX}$ removal for $\mathrm{Ag}_{3} \mathrm{PO}_{4}$ and $0.1 \mathrm{C} / \mathrm{Ag}_{3} \mathrm{PO}_{4}$; and (b) the high-resolution $\mathrm{XPS}$ spectrum of $\mathrm{Ag} 3 \mathrm{~d}$ in $\mathrm{Ag}_{3} \mathrm{PO}_{4}$ and $0.1 \mathrm{C} / \mathrm{Ag}_{3} \mathrm{PO}_{4}$ before and after three reaction cycles.

and $2.3 \mathrm{eV}$, respectively. ${ }^{9}$ The hybridization with hydrochar reduces the composite photocatalyst' band gap, thus promoting the light absorbance.

Fig. 5(b) shows the EIS spectra of the hydrochar, $\mathrm{Ag}_{3} \mathrm{PO}_{4}$, and $0.1 \mathrm{C} / \mathrm{Ag}_{3} \mathrm{PO}_{4}$ electrodes. The EIS spectra indicate the separation efficiency of the photocatalyst's electron-hole pairs. A smaller arc radius in a Nyquist diagram is an indication of an overall smaller charge-transfer resistance or, equivalently, a more facile charge transfer process at the electrode/electrolyte interface. ${ }^{41}$ Fig. 5(b) shows that the diameter of the arc radius on the EIS Nyquist plot of the $0.1 \mathrm{C} / \mathrm{Ag}_{3} \mathrm{PO}_{4}$ composite electrode is smaller than that of hydrochar and pure $\mathrm{Ag}_{3} \mathrm{PO}_{4}$, indicating that the $0.1 \mathrm{C} / \mathrm{Ag}_{3} \mathrm{PO}_{4}$ has the highest charge-separation and electrontransfer efficiency. Under visible light illumination, the photoinduced electrons of $\mathrm{Ag}_{3} \mathrm{PO}_{4}$ are transferred to the hydrochar, and the charge recombination is suppressed, which contributes to the improvement of the photocatalytic activity of the $0.1 \mathrm{C} /$ $\mathrm{Ag}_{3} \mathrm{PO}_{4}$.

The reactive oxidation species in the photocatalytic process were identified using different radical scavengers or quenchers. EDTA-Na ${ }_{2}$, isopropyl, and $p$-benzoquinone were added into the SMX degradation process to selectively quench $\mathrm{h}^{+},{ }^{\circ} \mathrm{OH}$, and $\mathrm{O}_{2}{ }^{\cdot-}$, respectively. As shown in Fig. 6(a) the addition of isopropyl and $p$-benzoquinone only slightly inhibit the progress of photocatalytic destruction. However, the addition of EDTA-Na significantly quenches the reactive oxidation species responsible for SMX degradation and consequently reduces the degradation rate from $98.2 \%$ to $23.7 \%$ after 90 min of irradiation. Thus, $\mathrm{h}^{+}$is the dominant reactive specie responsible for the photocatalytic process of the $\mathrm{Ag}_{3} \mathrm{PO}_{4}$-based composite, which is consistent with the previous study. ${ }^{44}$
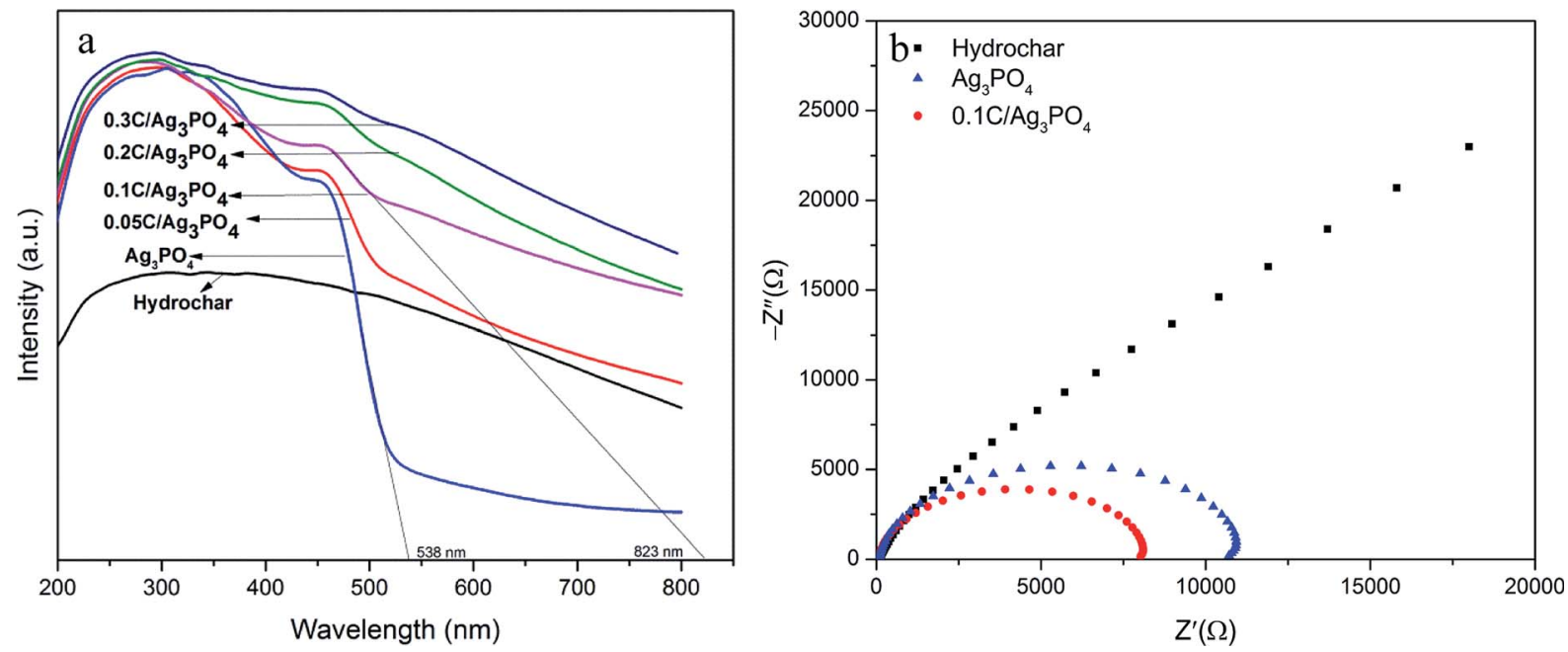

Fig. 5 (a) UV-vis diffuse reflectance spectra of the hydrochar $/ \mathrm{Ag}_{3} \mathrm{PO}_{4}$ composite; and (b) EIS for the hydrochar, $\mathrm{Ag}_{3} \mathrm{PO}_{4}, \mathrm{and}_{0.1 \mathrm{C} / \mathrm{Ag}_{3} \mathrm{PO}}$ 

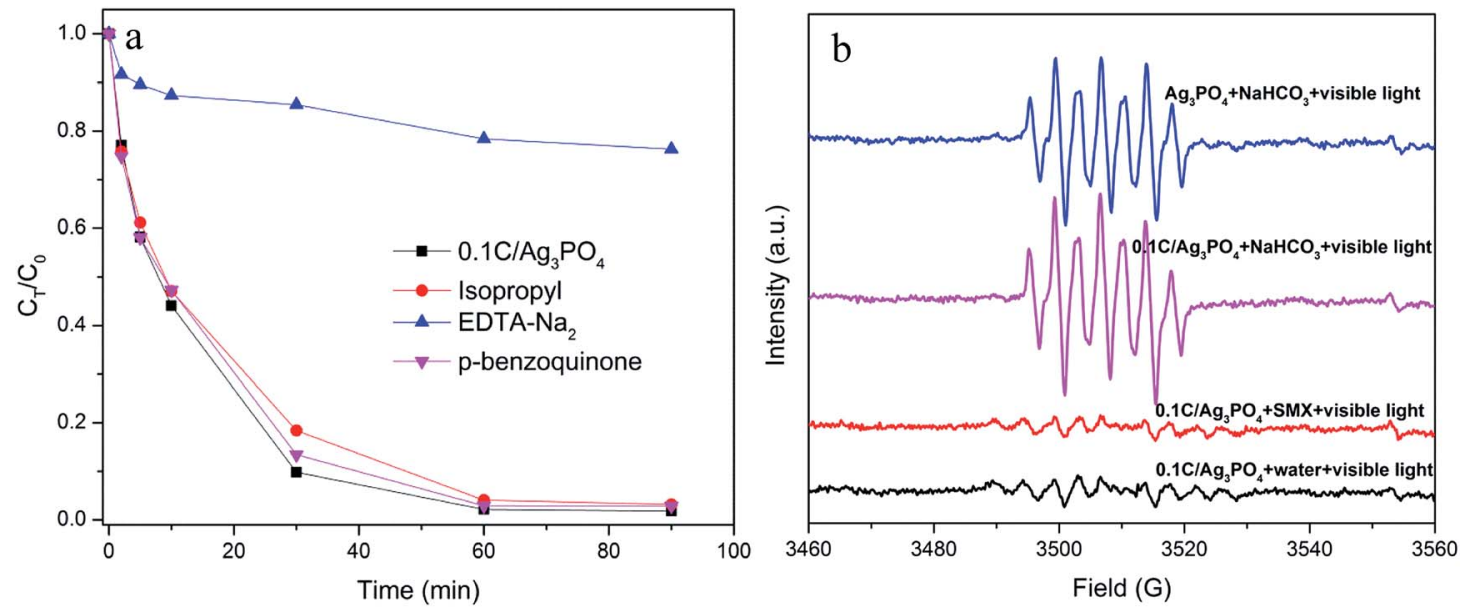

Fig. 6 (a) Degradation curves of SMX with additions of scavengers over $0.1 \mathrm{C} / \mathrm{Ag}_{3} \mathrm{PO}_{4}$ under visible light illumination; and (b) ESR spectra of radical adducts trapped by $\mathrm{DMPO}$ in $\mathrm{Ag}_{3} \mathrm{PO}_{4}$ and $0.1 \mathrm{C} / \mathrm{Ag}_{3} \mathrm{PO}_{4}$ systems: in a different dispersion for DMPO- ${ }^{\circ} \mathrm{OH}$.

ESR spectroscopy with DMPO was used to further verify the formation of ${ }^{\circ} \mathrm{OH}$ in the photodegradation system. Four spectra associated to the DMPO oxidation product, 5,5-dimethyl-1pyrrolidone-2-oxyl (DMPOX), are shown in Fig. 6(b), which is indicative of the DMPO oxidation by ${ }^{\circ} \mathrm{OH}$. For $0.1 \mathrm{C} / \mathrm{Ag}_{3} \mathrm{PO}_{4}$, weak ESR characteristic signals are detected in the SMX solution or pure water solution under visible light irradiation, which is because of negligible amounts of ${ }^{\circ} \mathrm{OH}$ in the solutions. In other words, the photogenerated $\mathrm{h}^{+}$in the $\mathrm{Ag}_{3} \mathrm{PO}_{4}$ valance band reacts slowly with the surface-bound water or hydroxyl group, generating a small amount of ${ }^{\circ} \mathrm{OH}$. However, the DMPOX signal intensities in $0.1 \mathrm{M} \mathrm{NaHCO}_{3}$ dispersions are much stronger than those in the SMX or pure water solutions, indicating that the presence of $\mathrm{OH}^{-}$in $\mathrm{NaHCO}_{3}$ solution speeds up the oxidation reactions of DMPO by ${ }^{\circ} \mathrm{OH}$ produced by $\mathrm{h}^{+}$oxidation. This constitutes additional evidence that $\mathrm{h}^{+}$is likely the dominant reactive species generating in the photocatalytic process for both pure $\mathrm{Ag}_{3} \mathrm{PO}_{4}$ and $0.1 \mathrm{C} / \mathrm{Ag}_{3} \mathrm{PO}_{4}$. In addition, the DMPOX signal intensity with $0.1 \mathrm{C} / \mathrm{Ag}_{3} \mathrm{PO}_{4}$ is slightly stronger than that of pure $\mathrm{Ag}_{3} \mathrm{PO}_{4}$, which shows that hydrochar facilitates production of radicals and enhances $0.1 \mathrm{C} / \mathrm{Ag}_{3} \mathrm{PO}_{4}$ photocatalytic activity.

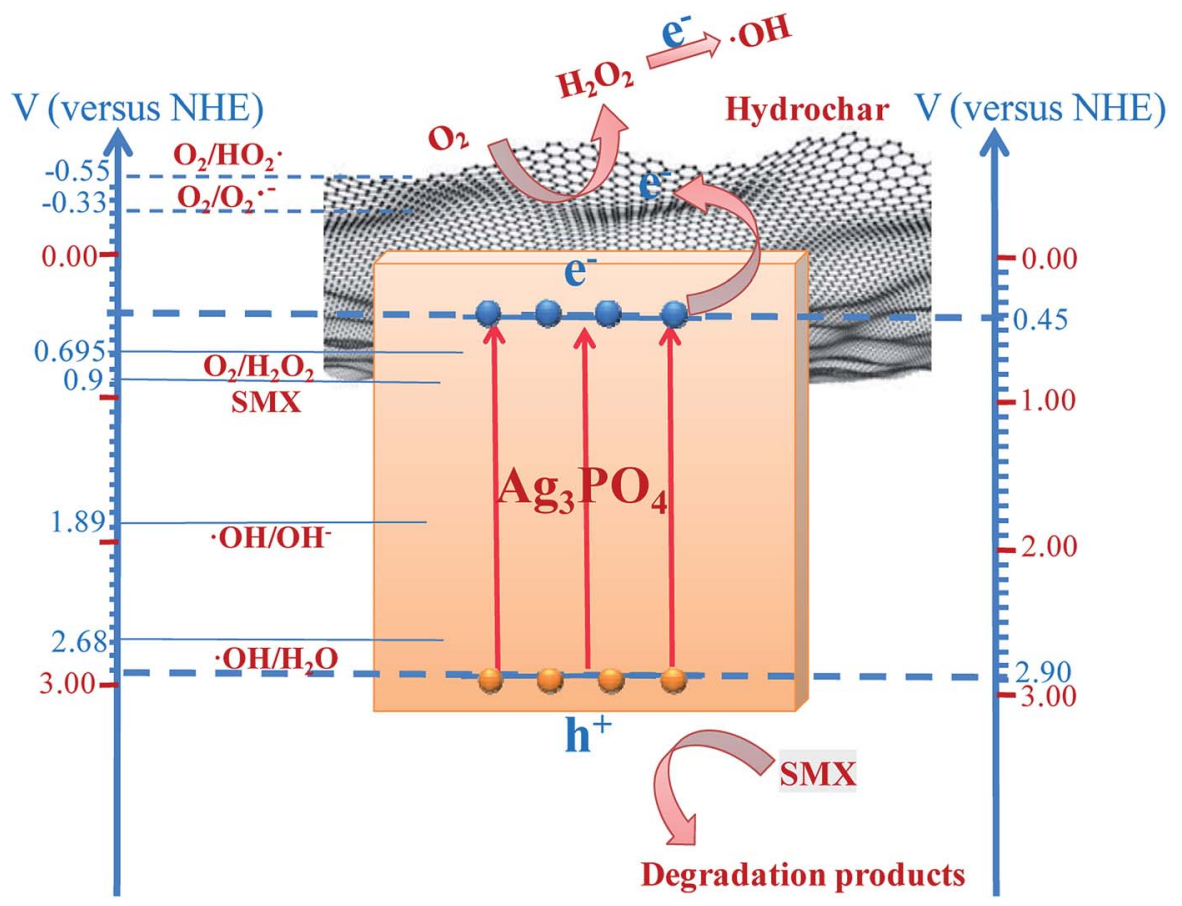

Fig. 7 Schematic of the proposed mechanism for SMX degradation under visible light irradiation and band structures of hydrochar/Ag ${ }_{3} \mathrm{PO}_{4}$ composite photocatalyst. 
In Fig. 7 , the potential charge separation, migration, and degradation process mechanisms under visible light irradiation are shown, where +0.45 and $+2.9 \mathrm{~V}$ are the respective conduction band (CB) and valence band (VB) potentials of $\mathrm{Ag}_{3} \mathrm{PO}_{4}$, compared to a normal hydrogen electrode (NHE), (denoted in blue on the right-hand $Y$-axis). The $\mathrm{Ag}_{3} \mathrm{PO}_{4}$ could be excited under visible light illumination due to the energy band gap. The VB potential of $\mathrm{Ag}_{3} \mathrm{PO}_{4}$ is more positive than SMX's oxidation potential $(0.9 \mathrm{~V}),{ }^{45,46} \mathrm{OH} / \mathrm{OH}^{-}(1.89 \mathrm{~V} / \mathrm{NHE}),{ }^{47}$ and ${ }^{\circ} \mathrm{OH} / \mathrm{H}_{2} \mathrm{O}$ $(2.68 \mathrm{~V} / \mathrm{NHE}),{ }^{48}$ indicating that the photogenerated holes have strong oxidative ability. The holes can oxidize $\mathrm{SMX}$ to $\mathrm{CO}_{2}$ and $\mathrm{H}_{2} \mathrm{O}$ (or other intermediate products) and $\mathrm{OH}^{-}$and $\mathrm{H}_{2} \mathrm{O}$ to ${ }^{\circ} \mathrm{OH}$. The potential variation between the $\mathrm{Ag}_{3} \mathrm{PO}_{4} \mathrm{VB}$ and $\mathrm{SMX}$ oxidative potential $(\Delta E=2.0 \mathrm{~V})$ is much greater than the difference between the VB potentials of $\mathrm{Ag}_{3} \mathrm{PO}_{4}$ and ${ }^{\circ} \mathrm{OH} / \mathrm{OH}^{-}$or ${ }^{\circ} \mathrm{OH} / \mathrm{H}_{2} \mathrm{O}\left(\Delta E_{1}=1.01 \mathrm{~V}\right.$ and $\left.\Delta E_{2}=0.22 \mathrm{~V}\right)$. This difference means that the photogenerated holes could preferentially oxidize the SMX instead of reacting with absorbed $\mathrm{OH}^{-}$or $\mathrm{H}_{2} \mathrm{O}$. This explains the minor effect of isopropanol as a ${ }^{\circ} \mathrm{OH}$ scavenger on the photocatalytic activity and the weak ${ }^{\circ} \mathrm{OH}$ signals in the SMX or water solution observed from the ESR analysis. However, the CB of the $\mathrm{Ag}_{3} \mathrm{PO}_{4}$ is too positive to reduce $\mathrm{O}_{2}$ to $\mathrm{O}_{2}{ }^{\cdot-}(-0.33 \mathrm{~V} / \mathrm{NHE})$ and $\mathrm{HO}_{2}{ }^{\cdot}(-0.55 \mathrm{~V} / \mathrm{NHE})^{49}$ through electrons produced in the $\mathrm{CB}$. Therefore, the production of such active oxygen species from single-electron reduction of $\mathrm{O}_{2}$ could not be attained during the photocatalytic process. The reduction potential of $\mathrm{O}_{2}$ to $\mathrm{H}_{2} \mathrm{O}_{2}(+0.695 \mathrm{~V} / \mathrm{NHE})^{49}$ is greater than the CB potential of $\mathrm{Ag}_{3} \mathrm{PO}_{4}$; therefore, the photogenerated electrons might be effectively moved to $\mathrm{O}_{2}$ to form $\mathrm{H}_{2} \mathrm{O}_{2}$ through a twoelectron reduction..$^{50}$ Furthermore, according to Fig. S4 in the ESI, $\uparrow$ the $\mathrm{H}_{2} \mathrm{O}_{2}$ produced in this system or externally added $\mathrm{H}_{2} \mathrm{O}_{2}$ could trap electrons and form ${ }^{\circ} \mathrm{OH} .{ }^{51}$

\section{Conclusions}

A novel nanocomposite of $\mathrm{Ag}_{3} \mathrm{PO}_{4}$ particles hybridized with hydrochar was synthesized via a chemical precipitation method. Compared with pure $\mathrm{Ag}_{3} \mathrm{PO}_{4}$ particles, there were significant changes in size and shape in the $\mathrm{Ag}_{3} \mathrm{PO}_{4} /$ hydrochar composite. The composite exhibited SMX and TOC photodegradation efficiency and recycling stability more than pure $\mathrm{Ag}_{3} \mathrm{PO}_{4}$. The incorporation of hydrochar enhanced the photocatalytic activity of $0.1 \mathrm{C} / \mathrm{Ag}_{3} \mathrm{PO}_{4}$ by increasing both the visible light absorption and separation of hole-electron pairs. Furthermore, the $\mathrm{h}^{+}$generated on the photocatalyst surface comprised main active species for the decomposition of adsorbed SMX. The addition of $\mathrm{H}_{2} \mathrm{O}_{2}$ in the photocatalytic system improved the electron-trapping efficiency and the formation of $\mathrm{OH}$, which enhanced the $0.1 \mathrm{C} / \mathrm{Ag}_{3} \mathrm{PO}_{4}$ photocatalytic activity. Taking into account the efficient and stable photodegradation of SMX, the hydrochar $/ \mathrm{Ag}_{3} \mathrm{PO}_{4}$ composite holds great potential as a sustainable visible-light-responsive photocatalyst for water remediation and pollutant degradation.

\section{Conflicts of interest}

There are no conflicts to declare.

\section{Acknowledgements}

This research was financially supported by the Youth Talent Development Plan of Shanghai Municipal Agricultural System (Grant No. 20180126), the State Key Laboratory of Pollution Control and Resource Reuse Foundation (Grant No. PCRRF18001), the Shanghai Agriculture Applied Technology Development Program (Grant No. 2019-02-08-00-12-F01136), and Shanghai Municipal Science and Technology Commission (Grant No. 19295801000).

\section{References}

1 Z. Yi, J. Ye, N. Kikugawa, T. Kako, S. Ouyang, H. StuartWilliams, H. Yang, J. Cao, W. Luo, Z. Li, Y. Liu and R. L. Withers, Nat. Mater., 2010, 9, 559-564.

2 H. Wang, Y. Bai, J. Yang, X. Lang, J. Li and L. Guo, Chem.-Eur. J., 2012, 18, 5524-5529.

3 X. Yang, L. Tian, X. Zhao, H. Tang, Q. Liu and G. Li, Appl. Catal., B, 2019, 244, 240-249.

4 F. Wu, F. Zhou, Z. Zhu, S. Zhan and Q. He, Chem. Phys. Lett., 2019, 724, 90-95.

5 H. Cai, L. Sun, Y. Wang, T. Song, M. Bao and X. Yang, Chem. Eng. J., 2019, 369, 1078-1092.

6 J. Liu, F. Xie, R. Li, T. Li, Z. Jia, Y. Wang, Y. Wang, X. Zhang and C. Fan, Mater. Sci. Semicond. Process., 2019, 97, 1-10.

7 Y. Chang, K. Yu, C. Zhang, R. Li, P. Zhao, L.-L. Lou and S. Liu, Appl. Catal., B, 2015, 176-177, 363-373.

8 C. Zhang, K. Yu, Y. Feng, Y. Chang, T. Yang, Y. Xuan, D. Lei, L.-L. Lou and S. Liu, Appl. Catal., B, 2017, 210, 77-87.

9 L. Zhou, W. Zhang, L. Chen, H. Deng and J. Wan, Catal. Commun., 2017, 100, 191-195.

10 L. Chen, S. Yang, Y. Huang, B. Zhang, F. Kang, D. Ding and T. Cai, J. Hazard. Mater., 2019, 371, 566-575.

11 Y. Duan, L. Deng, Z. Shi, L. Zhu and G. Li, Chem. Eng. J., 2019, 359, 1379-1390.

12 M. M. Mian and G. Liu, RSC Adv., 2018, 8, 14237-14248.

13 S.-H. Kong, S.-K. Loh, R. T. Bachmann, S. A. Rahim and J. Salimon, Renewable Sustainable Energy Rev., 2014, 39, 729-739.

14 C. A. Mullen, A. A. Boateng, N. M. Goldberg, I. M. Lima, D. A. Laird and K. B. Hicks, Biomass Bioenergy, 2010, 34, 67-74.

15 W.-J. Liu, H. Jiang and H.-Q. Yu, Chem. Rev., 2015, 115, 12251-12285.

16 L. Lu, R. Shan, Y. Shi, S. Wang and H. Yuan, Chemosphere, 2019, 222, 391-398.

17 S. Li, Z. Wang, X. Zhao, X. Yang, G. Liang and X. Xie, Chem. Eng. J., 2019, 360, 600-611.

18 X.-Q. Liu, W.-J. Chen and H. Jiang, Chem. Eng. J., 2017, 308, 889-896.

19 H. S. Kambo and A. Dutta, Renewable Sustainable Energy Rev., 2015, 45, 359-378.

20 N. Chen, Y. Huang, X. Hou, Z. Ai and L. Zhang, Environ. Sci. Technol., 2017, 51, 11278-11287.

21 K. Sun, K. Ro, M. Guo, J. Novak, H. Mashayekhi and B. Xing, Bioresour. Technol., 2011, 102, 5757-5763. 
22 Y. O. Donar, S. Bilge, A. Sinag and O. Pliekhov, Chemcatchem, 2018, 10, 1134-1139.

23 G. Siedlewicz, M. Borecka, A. Bialk-Bielinska, K. Sikora, P. Stepnowski and K. Pazdro, Oceanologia, 2016, 58, 221-234.

24 L. Zhou, H. Deng, W. Zhang and Y. Gao, Fresenius Environ. Bull., 2015, 24, 1685-1691.

25 M. Li, H. Huang, S. Yu, N. Tian, F. Dong, X. Du and Y. Zhang, Appl. Surf. Sci., 2016, 386, 285-295.

26 Q. Yan, M. Xu, C. Lin, J. Hu, Y. Liu and R. Zhang, Environ. Sci. Pollut. Res., 2016, 23, 14422-14430.

27 Y. Bi, S. Ouyang, N. Umezawa, J. Cao and J. Ye, J. Am. Chem. Soc., 2011, 133, 6490-6492.

28 W. Yao, J. Yang, J. Wang and Y. Nuli, Electrochem. Commun., 2007, 9, 1029-1034.

29 A. B. Fuertes, M. C. Arbestain, M. Sevilla, J. A. Macia-Agullo, S. Fiol, R. Lopez, R. J. Smernik, W. P. Aitkenhead, F. Arce and F. Macias, Aust. J. Soil Res., 2010, 48, 618-626.

30 S.-X. Zhao, N. Ta and X.-D. Wang, Energies, 2017, 10, 15.

31 L. Pi, R. Jiang, W. Zhou, H. Zhu, W. Xiao, D. Wang and X. Mao, Appl. Surf. Sci., 2015, 358, 231-239.

32 X. Wang, X. Wang, J. Zhao, J. Song, L. Zhou, R. Ma, J. Wang, X. Tong and Y. Chen, Catal. Sci. Technol., 2017, 7, 2335-2346.

33 Q. Cao, L. Xiao, L. Zeng, C. Cao and J. Wang, Powder Technol., 2017, 321, 1-8.

34 L. Zhao, X. F. Chen, X. C. Wang, Y. J. Zhang, W. Wei, Y. H. Sun, M. Antonietti and M. M. Titirici, Adv. Mater., 2010, 22, 3317-3321.

35 G. M. An, W. H. Ma, Z. Y. Sun, Z. M. Liu, B. X. Han, S. D. Miao, Z. J. Miao and K. L. Ding, Carbon, 2007, 45, 1795-1801.
36 Q. Xiang, D. Lang, T. Shen and F. Liu, Appl. Catal., B, 2015, 162, 196-203.

37 Z. Mu, J. Hua, S. Kumar Tammina and Y. Yang, Colloids Surf., A, 2019, 578, 123643.

38 Y. Hou, F. Zuo, Q. Ma, C. Wang, L. Bartels and P. Feng, J. Phys. Chem. C, 2012, 116, 20132-20139.

39 W. Zhai, G. Li, P. Yu, L. Yang and L. Mao, J. Phys. Chem. C, 2013, 117, 15183-15191.

40 H. Zhang, Z. Wang, R. Li, J. Guo, Y. Li, J. Zhu and X. Xie, Chemosphere, 2017, 185, 351-360.

41 L. Liu, Y. Qi, J. Lu, S. Lin, W. An, Y. Liang and W. Cui, Appl. Catal., B, 2016, 183, 133-141.

42 L. Zhou, O. G. Alvarez, C. S. Mazon, L. Chen, H. Deng and M. Sui, Catal. Sci. Technol., 2016, 6, 5972-5981.

43 P. Dong, Y. Wang, B. Cao, S. Xin, L. Guo, J. Zhang and F. Li, Appl. Catal., B, 2013, 132-133, 45-53.

44 Y. Chai, J. Ding, L. Wang, Q. Liu, J. Ren and W.-L. Dai, Appl. Catal., B, 2015, 179, 29-36.

45 P. Gamache, R. McCarthy, J. Waraska and I. Acworth, Am. Lab., 2003, 35, 21-25.

46 F. Gagné, C. Blaise and C. André, Ecotoxicol. Environ. Saf., 2006, 64, 329-336.

47 J. F. Dai, T. Xian, L. J. Di and H. Yang, J. Nanomater., 2013, 642897, 5 .

48 W. Yin, W. Wang and S. Sun, Catal. Commun., 2010, 11, 647650.

49 M. Miyauchi, Phys. Chem. Chem. Phys., 2008, 10, 6258-6265.

50 H. Katsumata, M. Taniguchi, S. Kaneco and T. Suzuki, Catal. Commun., 2013, 34, 30-34.

51 B. H. J. Bielski, D. E. Cabelli, R. L. Arudi and A. B. Ross, J. Phys. Chem. Ref. Data, 1985, 14, 1041-1100. 